\title{
Nicole Chareyron, Pilgrims to Jerusalem in the Middle
}

\section{Ages}

Trad. W. Donald Wilson. New York, Columbia University Press, 2005, 287

p.

[Trad. de : Les pèlerins de Jérusalem au Moyen-Âge. L'aventure du Saint Voyage d'après Journaux et Mémoires, Préf. de Pierre-André Sigal. Paris, Éditions Imago, 2000, 296 p.]

\section{Sylvia Chiffoleau}

\section{(2) OpenEdition Journals}

\section{Édition électronique}

URL : http://journals.openedition.org/assr/3891

DOI : 10.4000/assr.3891

ISSN : $1777-5825$

\section{Éditeur}

Éditions de l'EHESS

\section{Édition imprimée}

Date de publication : 1 décembre 2006

Pagination : 115-283

ISBN : 2-7132-2124-2

ISSN : 0335-5985

\section{Référence électronique}

Sylvia Chiffoleau, "Nicole Chareyron, Pilgrims to Jerusalem in the Middle Ages », Archives de sciences sociales des religions [En ligne], 136 | octobre - décembre 2006, document 136-25, mis en ligne le 12 février 2007, consulté le 21 septembre 2020. URL : http://journals.openedition.org/assr/3891 ; DOI https://doi.org/10.4000/assr.3891 


\section{Nicole Chareyron, Pilgrims to Jerusalem in the Middle Ages}

Trad. W. Donald Wilson. New York, Columbia University Press, 2005, 287 p.

[Trad. de : Les pèlerins de Jérusalem au Moyen-Âge. L'aventure du Saint Voyage d'après Journaux et Mémoires, Préf. de Pierre-André Sigal. Paris, Éditions Imago, 2000, 296 p.]

\section{Sylvia Chiffoleau}

1 S'appuyant sur un riche corpus de plus d'une centaine de récits de pèlerinage en Terre sainte rédigés du XIII ${ }^{\mathrm{e}}$ au XVI $\mathrm{X}^{\mathrm{e}}$ siècle, mais dont la plupart datent des $\mathrm{XIV}^{\mathrm{e}}$ et $\mathrm{XV}^{\mathrm{e}}$ siècles, l'auteur retrace le pieux et dangereux voyage qui, après les Croisades, portent certains croyants vers les lieux bibliques et, plus largement, en Orient. Ces récits de pèlerinage émergent alors comme genre littéraire dans lequel les auteurs portent témoignage de ce qu'ils ont vu mais aussi se livrent, se mettent en scène, se confrontent à l'histoire et à l'altérité.

2 Le dévoilement du voyage sacré à partir de ces récits se déroule en seize chapitres retraçant le parcours des pèlerins de Venise, lieu de départ privilégié, jusqu'au retour, égrenant les grandes étapes, s'attardant à Jérusalem et en Terre sainte, bien sûr, mais aussi en Égypte, du Sinaï à Alexandrie. Ces pèlerins de la fin du Moyen Âge sont riches des expériences et des récits antérieurs, ceux des Croisades notamment, et se présentent désormais non plus sous la figure du conquérant mais sous celle de l'intellectuel, aux origines sociales diverses, et « voyagent avec un bagage mental qu'ils projettent sur le monde ». Si la dévotion reste au fondement de leur démarche, ils s'éveillent aux «singularitez» qu'ils rencontrent, se livrent au cours du voyage à maintes observations et se révèlent voyageurs profanes tout autant que pèlerins. Certains de ces pèlerins sont des habitués, d'autres sont chargés de missions secrètes en Orient, tous ont le désir de faire connaître ce qu'ils ont vu. Le genre même du récit de pèlerinage évolue en conséquence : il est volontairement destiné à autrui, emprunte de plus en plus la langue vernaculaire et se mue parfois en littérature. 
3 Si nombre de routes mènent en Orient, c'est donc de Venise que partent, au printemps, après une émouvante cérémonie d'adieu, la plupart des pèlerins. Dans leurs récits, ceux-ci évoquent leur itinéraire (terme souvent employé dans les titres des ouvrages) jusqu'à la Cité des Doges, les distances parcourues, les difficultés rencontrées. Puis surgit Venise qui émerveille d'abord par la profusion de ses reliques puis, de plus en plus, à la fin du Xve siècle, par la beauté de ses monuments, sa modernité, l'activité de son industrie navale et l'exubérance de ses processions des fêtes de printemps. Les pèlerins s'y groupent en compagnies et sont pris en charge par les patrons des vaisseaux signalés d'une croix rouge qui leur sont destinés. L'organisation du pèlerinage est dûment contrôlée par le Sénat qui ne cesse de légiférer pour éviter les abus. Une fois le contrat passé avec un patron, le pèlerin doit s'acquitter d'une somme oscillant entre quarante à soixante ducats pour un aller-retour Venise-Jaffa. Plus ou moins bien installés, les pèlerins embarquent enfin pour un voyage de cinq semaines. La mer est pour beaucoup d'entre eux chose inconnue, effrayante. Là encore, nous dit l'auteur, quand le Moyen Âge s'étire et s'approche de l'ère de l'imprimerie, les pèlerins font l'apprentissage du récit profane, celui de la vie à bord, de la découverte des escales, des dangers de la navigation. Puis apparaît enfin la Terre sainte, d'abord sous les traits de "Jaffa la désolée ». Soumis à d'interminables formalités, les pèlerins peuvent mesurer le peu de sympathie qu'ils suscitent chez les habitants et les autorités avant d'être accueillis à Ramleh par les Franciscains qui les prennent en charge et organisent les pieuses visites. La visite de Jérusalem se fait en effet selon des itinéraires et des rituels précis afin de retrouver les souvenirs bibliques dans une ville devenue musulmane. Le séjour n'y dure pas moins de deux semaines. Au SaintSépulcre, point d'orgue de la visite où les pèlerins passent trois nuits, ceux-ci rencontrent, avec curiosité, mais sans guère de connaissances préalables, la diversité des Églises chrétiennes et de leurs liturgies. Les pèlerins se rendent ensuite à Bethléem puis se risquent à quelques excursions plus dangereuses au bord du Jourdain, de la mer Morte, plus rarement en Galilée, parfois jusqu'à Damas. L'altérité à laquelle est confronté le pèlerin, celle du musulman incompris, celle du Bédouin jugé sauvage, s'inscrit dans une perception qui préserve encore bien des traces de l'héritage critique, voire intolérant, des Croisades mais s'ouvre aussi à une curiosité naissante pour un ailleurs exotique, pour la singularité de l'autre. Si beaucoup de pèlerins rentrent chez eux après la visite de Jérusalem, certains poursuivent le voyage vers Sainte-Catherine du Sinaï. Ils affrontent alors le désert, lieu hostile et dangereux dont la narration offre à l'auteur l'opportunité de se faire acteur, parfois héroïque, et de donner quelques prémices d'une esthétique du désert qui sera largement exploitée à l'époque moderne. Après le pèlerinage aux lieux bibliques du Sinaï, les voyageurs se rendent au Caire, ville gigantesque, cosmopolite et grouillante, perçue par ces hommes de la fin du Moyen Âge comme une ville de lumière mais dont ils ont quelque mal à cerner la société et la vie politique. Ils visitent les pyramides qui, sous leur plume, commencent à sortir du mythe pour devenir objet de curiosité et bientôt d'étude. Ils mettent leurs pas dans ceux de la sainte Famille, poussent jusqu'aux couvents du désert, évoquent le rêve de la percée d'un canal entre Méditerranée et mer Rouge. Ils remontent enfin le Nil jusqu'à Alexandrie où ils pénètrent après force tracasseries administratives et frais de douanes. Qu'il se fasse depuis Jaffa ou au terme du voyage en Égypte, le retour est encore marqué de découvertes nouvelles, de maintes péripéties. Certains ne verront d'ailleurs pas la fin du voyage. Ceux qui rentrent se livrent alors au récit, récit dont la subjectivité est assumée, voire revendiquée par les auteurs et qui offre à ceux qui ne peuvent 
l'entreprendre une représentation imaginée du pèlerinage aux lieux saints. Tous ces auteurs partageaient, en ce temps d'émergence des sensibilités individuelles, « cette aspiration à transmettre, selon l'humeur, le goût du sel ou le dégoût du sable ».

4 Au-delà du récit qui restitue la substance du voyage sacré à la fin du Moyen Âge, l'auteur pointe deux éléments qu'il aurait été intéressant de voir plus amplement développés. Se pose d'abord la passionnante question de la façon d'exprimer par les mots les réalités nouvelles rencontrées en voyage, et bien sûr l'altérité. La réflexion sur le lexique et le style scripturaire est, ici, juste esquissée. Il en est de même du phénomène d'individuation, justement évoqué par l'auteur mais non pas soumis à une analyse serrée. D'un genre convenu surgissent en effet des personnalités diverses qui préparent l'humanisme du lendemain, un changement de vision du monde. En l'absence de choix analytiques fermes, les anecdotes livrées, émaillées de réflexions plus poussées, dessinent certes une geste pérégrine passionnante mais laissent dans l'ombre bien des questions que celle-ci soulève. Quoi qu'il en soit, l'ouvrage rend compte finement d'une période qui forme un chapitre peu connu de la généalogie des voyages en Orient. 